IZA DP No. 5601

Health and Well-Being in the Crisis

Nikolaos Askitas

Klaus F. Zimmermann

March 2011

Forschungsinstitut zur Zukunft der Arbeit Institute for the Study of Labor 


\title{
Health and Well-Being in the Crisis
}

\author{
Nikolaos Askitas \\ $I Z A$ \\ Klaus F. Zimmermann \\ IZA and University of Bonn
}

Discussion Paper No. 5601

March 2011

IZA

P.O. Box 7240

53072 Bonn

Germany

Phone: +49-228-3894-0

Fax: +49-228-3894-180

E-mail: iza@iza.org

Any opinions expressed here are those of the author(s) and not those of IZA. Research published in this series may include views on policy, but the institute itself takes no institutional policy positions.

The Institute for the Study of Labor (IZA) in Bonn is a local and virtual international research center and a place of communication between science, politics and business. IZA is an independent nonprofit organization supported by Deutsche Post Foundation. The center is associated with the University of Bonn and offers a stimulating research environment through its international network, workshops and conferences, data service, project support, research visits and doctoral program. IZA engages in (i) original and internationally competitive research in all fields of labor economics, (ii) development of policy concepts, and (iii) dissemination of research results and concepts to the interested public.

IZA Discussion Papers often represent preliminary work and are circulated to encourage discussion. Citation of such a paper should account for its provisional character. A revised version may be available directly from the author. 
IZA Discussion Paper No. 5601

March 2011

\section{ABSTRACT}

\section{Health and Well-Being in the Crisis}

The internet has become an important data source for the Social Sciences because these data are available without lags, can be regarded as involuntary surveys and hence have no observer effect, can be geo-labeled, are available for countries across the globe and can be viewed in continuous time scales from the micro to the macro level. The paper uses internet search data to document how the great economic crisis has affected people's well-being and health studying the US, Germany and a cross section of the G8 countries. We investigate two types of searches which capture self-diagnosis and treatment respectively: those that contain the words 'symptoms' and 'side effects'. Significant spikes for both types of searches in all three areas (US, Germany and the G8) are found, which are coincident with the crisis and its contagion timeline. An array of due diligence checks are performed and a number of alternative hypotheses are excluded to confirm that the search spikes imply an increase in malaise.

JEL Classification: $\quad$ C81, E32, I1, L86

Keywords: well-being, symptoms, side effects, Gallup, economic crisis, financial crisis, ill-being

Corresponding author:

Nikolaos Askitas

IZA

P.O. Box 7240

53072 Bonn

Germany

E-mail: askitas@iza.org

\footnotetext{
* We thank Hilmar Schneider, Konstantinos Tatsiramos and Rainer Winkelmann for reading earlier versions of the manuscript and the participants of IZA's Brown Bag Seminar for interesting comments.
} 


\section{Introduction}

Looking at internet search activity in the US during the crisis we are bound to find evidence of the crisis' impact. ${ }^{2}$ We focus our attention on two types of Google searches which we think are related to ill-being and health: ones which contain the word "symptoms" (we will be referring to those as "symptoms searches") and ones which contain "side effects" (which we will be referring to as "side effect searches"). Examples of such searches are ' depression symptoms" , ' 'anxiety symptoms') or '"hard attack symptoms') as well as 'prozac side effects', or ' $x a n a x$ side effects"'. The union of the two types of searches will be referred to as "malaise searches". We show that spikes coincident to the crisis do arise in the US, Germany but also across the G8 countries.

We document a delay in the German surge with respect to those in the US which is concordant with the contagion timeline of the crisis. Evidence such as the phase shift between the US and Germany as well as the cross sectional nature of the phenomenon significantly reduces the probability that the correlation of the crisis with the surge in symptoms and side effect searches is spurious. Furthermore it is reasonable to argue that malaise searches are bound to be related to well-being and health in one way or another: a search for "depression symptoms" may come from a hypochondriac, a medical buff, someone who may be in psychological stress or have a loved one who is or an "e-patient" ${ }^{3}$ but in any case it is related to health and well-being. Similarly a search for "xanax side effects" most likely indicates someone who is consuming the known antidepressant or shopping for medication for oneself or for a loved one thereof. In both cases a significant surge in the aggregate numbers of these searches is a phenomenon worth exploring as the likelihood it implies increased malaise is more than apparent. We know ${ }^{2}$ for example that "adults who, in the past 12 months, have provided unpaid care to a parent, child, friend, or other loved one" are among the most likely groups to look online for health information. Our interpretation is that these searches do indeed indicate increased malaise: symptoms searches express self-diagnosis while side effect

\footnotetext{
2 "Some 69\% of Americans have used the internet to cope with the recession as they hunt for bargains, jobs, ways to upgrade their skills, better investment strategies, housing options, and government benefits", http://authoring. pewinternet.org/Reports/2009/11-The-Internet-and-the-Recession. aspx moreover "eight in ten internet users look online for health information, making it the third most popular online activity", http://www.pewinternet.org/ $\sim /$ media//Files/Reports/2011/PIP \_HealthTopics.pdf. Since $25 \%$ of adults are not online this mean $59 \%$ of the total population seek health information online.

${ }^{3}$ The term participatory medicine is well know in the US. The Society for Participatory Medicine was founded in July of 2009: http://participatorymedicine.org.
} 
searches imply that treatment is being applied. Since we cannot construct counterfactual societal realities in the lab in which we insert or subtract a recession our task is to make as airtight a case as possible for our narrative. We do so by means of alternative data sources or other statistical due diligence which helps reject alternative hypothesis. Doing so solely based on aggregate data is of course not an easy task. ${ }^{4}$

The rest of this paper is organized as follows ${ }^{5}$. In Section 2 we reconstruct aspects of the timeline of the crisis and in Section 3.2 we review the available literature which uses Google Insights as well as the one on the effect of the business cycle on health and well-being while in Section 4 we describe the Gallup well-being indices which give us a first look at the impact of the crisis on well-being. Section 5 describes our main data source Google Insights and in Sections 6.1 and 6.2 we discuss search intensity for "symptoms" and "side effect" and connect this with mental and physical well-being. In Section 6.3 we perform statistical forensics in order to reject alternative hypotheses and strengthen our assertions and Section 7 concludes our paper.

\section{A brief timeline of the crisis}

The current economic crisis which showed its first signs as early as 2007 was first seen as a US finance crisis which became acute in the dramatic fall of 2008. It subsequently went on to "mutate" into an economic crisis "infecting" most of the industrialized world by the spring of 2009 and is by many accounts still underway. The crisis has impacted the world in profound ways which policy and decision makers as well as economists are now busily sorting out.

As early as in August of 2007 US credit markets were impacted by the collapse of two mortgage related hedge funds of Bear Stearns, at the time the fifth largest securities firm in the US. Bear Stearns ended up losing over $90 \%$ of its value soon after and was eventually bought by JPMorgan. The US labor market was beginning to show signs of a downturn as US unemployment which was dropping since 2003 was now beginning to inch upwards. At the same time the Dow Jones Economic Sentiment Indicator (henceforth ESI) which measures the sentiment in press reporting was now becoming bleaker having hovered between 60 and 70 points (in a scale of 0 to 100) since 2005. All the while more and more homeowners were falling behind on their mortgage payments.

\footnotetext{
${ }^{4}$ Access to good samples of search microdata would help clear some of the issues we will discuss.

${ }^{5}$ All data used in this paper are public and in fact freely available on the internet. Whenever the data is proprietary we collected it from publicly available reports (available on the internet) and on occasion we had to dissect a CGI or two to programmatically capture publicly plotted data (as in the case of the Gallup well-being index).
} 
By September of 2008 Lehman Brothers, at the time the biggest US underwriter of mortgagebacked securities, was filing for bankruptcy and the two biggest US mortgage finance companies, Fannie Mae and Freddie Mac were being nationalized. The labor market was now deteriorating with unemployment up to $6.1 \%$ from $4.1 \%$ at its previous low in October 2006. The ESI bottomed out at just over 20 points having lost 60\% of its value as of July 2007. On September 182008 , then Treasury Secretary Henry Paulson and Fed Chairman Ben Bernanke were meeting with legislators trying to secure a $\$ 700$ billion emergency backstop. Bernanke reportedly argued " If we don't do this, we may not have an economy on Monday' '. The Troubled Assets Relief Program (henceforth TARP) was signed on October 03 of 2008. This is our cut-off date. We mark this date on our time series plots and observe Google search behavior before and after the TARP date $^{6}$.

In Germany as in the rest of Europe the drama unfolding across the Atlantic was still been viewed and felt as an American financial crisis. The DAX was following the Dow Jones Industrial index but the economic consequences were still not fully visible and the only question was the extend to which a US collapse would take down US imports and with it the GDPs of export countries like Germany. German GDP was showing mixed signs of a possible downturn in the first 3 quarters of 2008: while GDP was still growing year-over-year it was dropping compared to previous quarters. By the time the German GDP plunged to its lowest point in the first quarter of 2009, kurzarbeit ${ }^{7}$ was at its peak and unemployment reached its (considering the severity of the crisis moderate indeed) high in March of 2009, there was no doubt we had a German economic crisis. This is our mark for Germany where we start observing search spikes related to ill-being.

That the business cycle may have an impact on emotional and psychological well being is we think apparent. Job uncertainty, housing market volatility, income and equity erosion with the existential fears and anxiety they generate may reasonably be expected to impact mental health. Physical health may be expected to be impacted via the mental and psychological health channel as well as due to possible relaxation of on the job security precautions during a recession. This recession is different from any other in many qualitative ways, a fact many quantitative analysts

\footnotetext{
${ }^{6}$ The most dramatic time is the 60 days before that date but Oct 3 is by far the most memorable date to keep in mind.

${ }^{7}$ German for "short work", kurzarbeit describes a German labor market policy instrument which is used to absorb seasonal labor fluctuations by allowing employers to retain employees as opposed to firing. It was used in the crisis to stabilize the labor market.
} 
tend to forget often times. By that we mean something beyond the usual loss of coherence in long time series. One of the ways this recession is different is that it has been as closely reported upon as no other in history. ${ }^{8}$ This may have very well exacerbated the intensity of anxiety and malaise in the general population. In some way we may be witnessing "irrational sullenness" following "irrational exuberance" 9 Our point being that while the causes may be exaggerated their impact on health and well-being is real. This is comparable to expectations in financial markets: the illusional nature of optimistic or pessimistic expectations does not prevent them from having a real impact on market capitalization.

\section{Relevant references}

Our paper has a two fold aim: we want to use internet search data in order to say something about the impact of the crisis on health and well-being and by doing so we want to validate this type of data and alert social science workers to the possibilities it opens and the issues it comes with. We therefore want to devote this section to first review the literature which has used Google Insights already and subsequently review a portion of the literature which deals with well-being and the business cycle.

\subsection{Google Insights in the literature}

Google data has been used mainly to nowcast economic variables and to be more precise to "predict the present" (Varian \& Choi (2009)). In this approach one exploits the real time availability of such data vs a significant lag in the publication of "official data" (which is often revised subsequently) to predict economic variables of interest. In essence the core idea here is that such data is readily available in real time and hence provides a good, fast, real-time reporting of reality. The official data then serves as the benchmark to check the reporting against. The data has been used for consumption research (Kholodilin, Podstawski, \& Siliverstovs (2010), Schmidt \& Vosen (2010), Schmidt \& Vosen (2009)), housing prices (Kulkarni, Haynes, Stough, \& Paelinck (2009)), unemployment (Askitas \& Zimmermann (2009), D'Amuri \& Marcucci (2010)), finance

\footnotetext{
${ }^{8}$ The phenomenon is similar to the 2003 invasion of Iraq being like no other war: this was the birth of "embedded journalism".

9 "But how do we know when irrational exuberance has unduly escalated asset values, which then become subject to unexpected and prolonged contractions as they have in Japan over the past decade?", Alan Greenspan, chairman of the Federal Reserve Board in Washington, speech titled "The Challenge of Central Banking in a Democratic Society" before the American Enterprise Institute, December 5, 1996. http://www.federalreserve.gov/BOARDDOCS/ SPEECHES/19961205.htm
} 
(Sims (2010)) and policy (Bersier (2010)). It has also been used to enhance the performance of more traditional forecasting models as in Kholodilin, Podstawski, Siliverstovs, \& Bürgi (2009). Our own exercise on short term forecasting of German unemployment (Askitas \& Zimmermann (2009)) served us well in predicting a quiet labor market at a time when most experts thought it to be highly unlikely. In health analysis it has been used to predict flu trends (Ginsberg, Mohebbi, Patel, Brammer, Smolinski, \& Brilliant (2009)). A paper similar to ours with a more restricted focus is Tefft (2011).

\subsection{Business cycle and well-being}

There is extensive literature on the impact of unemployment and the business cycle on health and well-being. The general picture appears to be that there is a negative effect of unemployment on well-being as shown for example in Clark \& Oswald (1994). For a more comprehensive review of the relevant literature the reader could consult the relevant chapter of Frey (2008). The effect of the business cycle on health using aggregate measures is treated in Brenner (1973), Brenner (1975) and Brenner (September 15, 1979) as well as in Ruhm (2000). The impact of recessions on physical health is studied for example in Arinaminpathy \& Dye (2010) in the case of tuberculosis and in Martin-Moreno, Alfonso-Sanchez, Harris, \& Lopez-Valcarcel (2010) for cancer. In short the literature appears to point in the expected direction: unemployment and a slow business cycle

lead to increase in malaise although there may be a short term reverse effect in both directions (a recession will allow one to have more time to tend to health issues having a short term positive effect on health which disappears in the long run. Similarly a booming economy may have a partially negative influence on health to the extend to which it steals time from caring for ones health.)

\section{Well-being and the crisis: a first look}

The Gallup Well-being Index provides us with well-being measurements in the US starting in January 2008. It has therefore captured some of the impact of this crisis on health and well-being. The Indices are based on daily interviews of no less than a thousand respondents and what we plot here are publicly available monthly data. Figure 1 is our reproduction of these indices. All series are expressed as percentage of change relative to their value at time $t=T A R P$ (so they are all zero at the TARP date). Each of the six plots contains the composite index in addition to a component 
of the Gallup Well-being index. Before we comment on the development of these indices we would like to briefly describe them ${ }^{10}$ for the purpose of our exposition.

PHI The Physical Health Index is based on the following items: Sick days in the past month, Disease burden, Health problems that get in the way of normal activities, Obesity, Feeling well-rested, Energy, Colds, Flu and Headaches.

WEI The Work Environment Index measures the perception of ones work environment and includes Job satisfaction, Ability to use one's strengths at work, Supervisor's treatment (more like a boss or a partner), Supervisor creates an open and trusting work environment.

BAI The Basic Access Index measures access to necessities crucial to well-being and includes Satisfaction with community or area, Area getting better as a place to live, Clean water, Medicine, Safe place to exercise, Affordable fruits and vegetables, Feel safe walking alone at night, Enough money for food, Enough money for shelter, Enough money for healthcare, Visited a dentist recently, Access to a doctor and Access to health insurance.

LEI The Life Evaluation Index measures a self-evaluation of current and anticipated life situation (in five years). respondents provide a " 4 " or lower to both evaluations.

EHI The Emotional Health Index is based on respondents daily experiences and includes Smiling or Laughter, Being treated with respect, Enjoyment, Happiness, Worry, Sadness, Anger, Stress, Learning or doing something interesting, Depression.

HBI The Healthy Behavior Index includes Smoking, Eating healthy, Weekly consumption of fruits and vegetables and Weekly exercise frequency.

Notice that the Emotional (EHI) and the Life Evaluation Indices (LEI) were dropping much earlier than October 2008 while the Basic Access (BAI), Work Environment (WEI) and Physical Health (PHI) Indices were increasing all the way up to the TARP and took a sharp turn downwards right after that. Quite possibly while anxiety levels were increasing early on in accordance with reports of a financial crisis in the making (underway since 2007) the crisis was still being perceived

\footnotetext{
${ }^{10}$ More on the Gallup Well-being index and its methodology can be found under http://www . well-beingindex . com/ and http://www.well-beingindex.com/.
} 
as an ambient nuisance and an as yet unrealized threat. At the culmination of the finance crisis and the successive failures of the Too-Big-To-Fail corporations the threat begun to materialize and people's physical health took the hit together with work environment conditions and access to basic goods.

It is also interesting to see that the subjective well being indices (Emotional and Life Evaluation) recover relatively quickly (and in fact overcompensate) although the crisis was still in full swing a phenomenon well-known as adaptation. The more "objective" indices such as Physical Health and Basic Access recover much slower with the Work Environment index continuing to worsen as of February 2011. One component we left out so far is the Healthy Behaviors index (top right) which shows a clear seasonality swinging between the bikini season fitness in July and the low of Christmas season binge. The crisis can be seen here in that the excesses of Christmas 2008 were worse than the ones in 2007, 2009 and 2010, a sign of perhaps increased fatalism in the midst of an extremely over-reported finance crisis. Although Healthy Behavior recovers quickly out of the deep of 2008 gaining two points in Christmas of 2009 it clearly stagnates in 2010.

Finally the Life Evaluation Index ( which contains subjective evaluation of present life situation and anticipated life situation "five years from now") is the most volatile with a 30 percentage points spread when the Basic Access, Emotional Health and Physical Health indices have an almost 3 point spread and the seasonal Healthy Behaviors and the still falling Work Environment index have a close to 10-15 point spread. In the volatility of the Life Evaluation Index we see "animal spirits" and what we earlier called the real impact of "irrational sullenness".

It is clear from these indices that the crisis impacted the self reported mental, emotional and physical well being as well as the objective and subjective, experienced and remembered well-being.

\section{Google Insights}

In countries with high internet penetration online is a "place" where a large and diverse portion of human activity takes place. Entertainment, shopping, porn, research, business, health, news, computing, home, automobiles, sports, travel, games, finance, holidays are just some of the areas which span this online activity. Frankly speaking it is hard to imagine of a human activity which would not have an internet component. Search is a vital component of this activity in that it indexes the enormous stock of online "documents" and makes it tractable for the user population. The study of internet activity in general and in particular internet search is therefore a natural 
scientific endeavor both for the purpose of tuning the indexing and searching algorithms in order to make them more effective as well as for other purposes such as for example the social sciences. The latter is our field of interest.

An internet search has several attributes such as: a "userid" (who searches?), a "query" (what is being searched?), a "query time" (when is the search performed?), the "click url" (which if any of the results was selected) and an "item rank" (what was the rank of the "click url" among all the results?). Localization attributes of the origin of the search are also tractable such as geocoordinates, company, home or school network etc. A "query" may be viewed as a short utterance by the user i.e. as a short statement. In some sense, that is, a "query" may well be an answer the user is giving us to a question we did not pose which we can however guess with varying degrees of certainty. For example a classical interview could ask a female user a question of the form "Did you recently have unprotected sex?" and receive an answer or not. An answer may then be affirmative or not and it may be reliable or not. A search query of the form "plan b cost" or "morning after pill" is quite likely an affirmative answer to the same question which we now had to "reverse engineer". In a voluntary survey therefore we have certainty about the question but not about the answer whereas an internet query is an utterance (involuntary survey) which gives us a reliable answer to a possibly uncertain question. Being well aware of the interesting and difficult ethical issues involved we can argue that search queries are honest answers given under the assumption of privacy and as such valuable for research purposes.

Search microdata with demographics attached are not available at this time but we can to some extend make due with aggregate data. For example the share of searches including "job search" among all other searches on daily, weekly or monthly basis may give us an idea of the intensity by which job searches are performed. The latter kind of search macro data is by and large free of ethical issues. Since the summer of 2008 Google Insights ${ }^{11}$ makes this type of aggregate data available. The Google Insights service can be queried regarding the variation of the search intensity along any search term so long as it has "sufficient" volume (the restriction is meant to among other things prevent deanonymization). A Google Insights query has several parameters which can be chosen within some limits. These are regional, temporal, search term specific and Google category specific. Regional parameters may vary from country to city level

\footnotetext{
${ }^{11} \backslash$ tthttp://www.google.com/insights/search/
} 
depending on country, temporal parameters go as far back as 2004 and can be any desired interval (data is then daily or weekly depending on interval length) and the search term can be anything so long as it does not exceed a certain length. The search term may be composite in many ways. Disjunctions are possible i.e. ' 'employment + unemployment', will give you search intensity for all searches containing ' employment', or ' unemployment', Complements are possible ' 'employment -unemployment"' will give you search intensity for searches containing ' 'employment', without counting searches which contain ' unemployment', Finally a keyword or phrase can be quoted to restrict counting to the searches which contain the exact keyword or phrase. Google divides all search in categories such as "Health", "Automotive" etc. and search intensity along a certain keyword may be measured relative to a category. For example in order to capture the health related searches along symptoms of depression without the business cycle ones measurements can be made within the Health category. Comparative queries are possible: up to 5 search terms in a single geographic unit for any time interval or up to five geographic regions for a single search term and any time interval. Google Insights delivers time series which are scaled and normalized as follows: All data points of the time series will be normalized by dividing the search term volume with the total search volume in the reference time interval (day, week, month). This means if the keyword $K$ has $K_{i}$ searches in the $i^{t h}$ reference time point and the total Google search volume therein is $G_{i}$ then the measurement we will see is $N\left(K_{i}\right)=K_{i} / G_{i}$. The latter will then be scaled by setting the maximum value equal to 100 and scaling the rest accordingly i.e. the series we will get from Google Insights is then $I\left(K_{i}\right)=\frac{N\left(K_{i}\right)}{\max _{i}\left\{N\left(K_{i}\right)\right\}} 100$. Finally sampling is involved in forming these numbers and the results are robust for high enough values. For low values results may be unreliable and caution should be applied.

One of the advantages of looking at search data (besides the fact that it is easily available in real time) is that it, unlike voluntary surveys, has no observer effects. It is well known for example that depression in men is underreported because "depression is a female disease" (see e.g. Porche (2005) and Wilhelm (2010)). The general picture is that as men grow older they are less likely to report depression but more likely to commit suicide than women. Men however should have no inhibitions in searching for information about symptoms of depression in the privacy of their home and their internet sessions. ${ }^{12}$

\footnotetext{
${ }^{12}$ This may be useful in many types of research. Since 2004 there are on the average $3-4$ times more searches
} 


\section{Health Searches}

With the advent of the internet there has been a democratization of knowledge whose consequences, both positive and negative, can be felt in all aspects of life. Patients now more often than before confront their doctors with a possible diagnosis rather than with a description of their symptoms. According to data from the Pew Internet \& American Life Project, $80 \%$ of internet users have looked online for health information which makes doing so a widespread activity among internet users in the US. We expect similar numbers in Germany and everywhere where there is sufficient internet penetration. Our analysis of Google Search for symptoms and side effects is therefore well founded on ubiquity and adoption and should therefore have little if any bias from a possible selection effect.

\subsection{Symptoms}

Typing ' 'symptoms') as the first word of a query in Google returns several completion options such as 'symptoms of mono'" or "'symptoms of diabetes') or '"symptoms of pregnancy"' etc. On the other hand by typing ' depression'" one is offered ' 'depression symptoms' as one of the completion options and the same goes for ' "pregnancy', ' 'anxiety' ' or ' "heart attack' ' etc. So Google allows us a sneak peak at symptoms related searches. There are many reasons why an internet user would search for symptoms of a disease. Most of the time it must be an attempt of a home made self-diagnosis or of someone they care about. The reason people search (instead of say go to the doctor) may just be because there is a stock of knowledge out there they can tap into which then allows them to better use a subsequent doctor's visit or in order to learn about the experience of other patients with the same condition (e.g. pregnancy) or to diagnose themselves for malaise which they feel embarrassed about (i.e. men and depression symptoms, married and sexually transmitted diseases etc) or even because they are a hypochondriac or a medicine buff. In the US the terms "e-patient" and "participatory medicine" are by now well known ${ }^{13}$. Capturing the overall aggregate volume of this search activity is hence related in a multitude of ways to malaise.

Figure 2 shows us the intensity of symptoms searches in the US and Germany. The rise starts much earlier in the US and in fact it starts soon after the dramatic September of 2008 which is

for "'child porn"' than for "girls volleyball', On the other hand a survey question of the type "'Are you aroused by children's sexual abuse?' ' is unlikely to get any affirmative answers.

${ }^{13}$ In July 2009 the Society for Participatory Medicine was founded: http://participatorymedicine.org. 
the break out of the Financial Crisis. In Germany where a Financial Crisis had no immediate obvious impact the surge occurs soon after April of 2009 (the high point of a rather moderate rise in unemployment but also the high point of unemployment leantering kurzarbeit) at which point the Financial Crisis mutated to an Economic Crisis. They both peak in April of 2010.

We think that this clearly demonstrates that the surge in 'symptoms'" searches is caused by the crisis. Whether it means a rise in the so called "participatory medicine" or a rise in "pathogeny" and "malaise" it is at this point unclear and we will discuss it further. Before we do so we would like to make two remarks on Figure 2. The dotted line shows us all searches which contain symptoms (including the ones which contain $f l u$, swine or H1N1). The solid line shows us searches for symptoms without the aforementioned keywords in order to avoid the noise coming from the H1N1 epidemic which is unrelated to the crisis. As a byproduct we see the impact of the epidemic on the searches for its symptoms. This is yet another verification that google searches have content of interest for social sciences and epidimiology. We see in the graphs that there is indeed significant impact of H1N1 related searches. Furthermore we see that the fact that the flu reached Europe with a delay is reflected in the difference between the first bumps in the US case vs the German case and we also see that the flu had slowed down since.

Our second remark has to do with absolute volumes of these searches. While we cannot really tell "how many searches included" or "how many people searched for" symptoms we can use a ratio of search intensity for symptoms over say search intensity for the most popular sport for which we have good intuition of its size: football. Figure 3 shows that in 2009 both ratios rise sharply. This serves to give us a kind of quantification of these numbers:

In the US for every 100 football searches in 2007 we had about 40 for symptoms. By 2009 we had about 50 and by 2010 over 60 . In the German case it went from under $20 \%$ to over $50 \%$ in 2010 .

A few remarks are due here on Figure 3. The comparison is done globally (not in the Health category) because this would put football searches at a disadvantage. By doing so we inevitably introduce noise in the symptoms searches (non health related). The comparison is nonetheless helpful since over $75 \%$ of the symptoms searches fall within the Health Category in both countries. In order to get a feeling for the size of searches containing the word football or (fussball) we need to note that in Germany the mean of ' fussball + fußball' ' searches since 2004 is a little over 
$50 \%$ of the mean of ' $p$ porn' ' searches while in the US the comparison comes to a little under $50 \%$. Considering that porn is the 4th most common activity on the internet (see Pass, Chowdhury, \& Torgeson (2006)) gives us an idea of the volumes involved.

We performed a number of other explorations all of which show that symptoms searches surge more intensely in comparison. One direction we looked at is other sports such as baseball or basketball. We also compared symptoms searches to "search white noise" such as the disjunction of all days of the week, the disjunction of all months, all arabic numerals, all latin alphabet letters etc. Finally we compared symptoms searches to searches containing each of the top 10 most common english words ${ }^{14}$.

We now want to return to the discussion of whether the crisis simply caused people to turn to the internet for health advice or whether it caused an increase of malaise. Quite likely it did both. Looking at Figure 4 we see that all symptoms searches spiked. In the graph we see the search intensity for symptoms broken down into three time series. The dotted line contains all symptoms searches. This time series contains the H1N1 epidemic so we subtract those and get a cleaned series (solid line). The dashed line is what we get by counting symptoms without those containing a number of associated terms. All series spike. Searches of symptoms of diseases with a lagged response to the crisis may contain more participatory medicine. For example while according to Martin-Moreno et al. (2010) cancer is expected to rise in economic downturns (changed working condition, cutting corners on safety etc) it is not something which spikes as easily as say anxiety symptoms. Nonetheless in the context of psychological distress and "irrational sullenness" even increases in symptoms searches of malaise with slow response may be an indication of generalized anxiety.

What supports the fact that the symptoms time series contains increased malaise is the fact that in the US the surge begins with the Finance Crisis in September of 2008 and in Germany with the Economic Crisis in the spring of 2009, that in Germany there is no organized "e-patient movement" and that unlike in the US where a less widespread health coverage may force people to self-diagnosis in times of economic downturn in Germany this is not the case: symptome searches increase despite a well-developed social security system. Supportive of increased malaise in the US is also the Gallup well-being index and its various components in Figure 1. Finally from Figure 5

\footnotetext{
${ }^{14}$ We used the ranking obtained from the American National Corpus an open data repository for language research and education: http://www.americannationalcorpus.org/SecondRelease/data/ANC-written-count.txt
} 
we see that the Google Category Health has grown by about $10 \%$ from its pre-crisis low to its postcrisis high while symptoms searches grew significantly more. Moreover for more responsive types of searches such as high blood pressure symptoms we expect that a spike contains more malaise than patient participation than in the case of less responsive ones such as chronic symptoms of lyme disease.

Our conclusion is that while we cannot tell which part of the increase in symptoms searches is related to participatory medicine and which to the crisis causing increased malaise we can say that it is due to both. The difficulty in validating this has also to do with the fact that in the searches there is malaise which may never express itself as health related expenditure or a doctor's visit either because of stereotyping (depression in men) or because the search spike is an expression of panic due to irrational sullenness.

We measured a number of other types of searches such as heartburn relief, acid reflux symptoms, heart attack symptoms, anxiety symptoms, stroke symptoms, bipolar symptoms all of which exhibit the same behavior. Figure 6 shows the search intensity for symptoms of high blood pressure in the US. Here and elsewhere in the US we can see the shocking spike of the signal within a very short time arount $t=$ TARP. Finally in Figure 7 we scaled US unemployment rate and symptoms searches in the US with their own maximum value as a reference value. We see that the unemployment rate would "explain" symptoms searches well. The same is not true in Germany since unemployment rose only moderately but a combination of unemployment rate and kurzarbeit would explain symptome searches well.

\subsection{Side Effects}

US prescription sales grew ${ }^{15}$ by $5.1 \%$ in 2009 to over $\$ 300$ billion compared to $1.8 \%$ growth in 2008. Moreover antidepressant sales grew by $4 \%$ in 2009 to 9.9 billion pushing the corresponding drug category one position up in the list of most consumed type of medication to number 4 . This data is consistent ${ }^{16}$ with Figure 8 which shows the growth for side effects searches in the US, assuming an increase in searches for side effects implies an increase in the consumption of medication. We believe this to be the case since the reason an internet user would search for

\footnotetext{
${ }^{15}$ Data by IMS Health (http://www.imshealth.com)

${ }^{16}$ Sales of pharmaceuticals as measured in total revenue does not always reflect the amount of pharmaceuticals consumed. Shrinking revenue is not incompatible with increasing consumption. This can occur when patents expire and cheaper alternatives brands or no name drugs emerge. Also according to IMS health the reduced growth in 2008 was partly due to the economic downturn. It seems as though an ensuing downturn affects consumption at first.
} 
say lexapro side effects is because she or someone she cares about is currently consuming Lexapro or because she compares lexapro side effects with xanax side effects in order to decide which is best suited for her. We believe side effect searches to be closely correlated with medication and to be less affected by an increase in participatory medicine. In other words unlike the case of symptoms searches where we see a crisis related increase which is partly due to increased malaise and partly due to increased participation by the "e-patients" in the case of side effects searches we believe that it is by far due to increased consumption of medicine. In the aggregate numbers this means an increase in searches of side effects implies an increase in medication consumption which implies increased malaise. In the cases of prescription medicine we know that this is medically verified malaise. In the cases of over the counter medicine we have self-reported, subjective malaise. Both are significant.

Explorations for side effects searches vs say football searches has similar results as for the symptoms searches in Section 6.1. Figure 9 shows us the searches for side effects of 4 well known antidepressants: lexapro, celexa, xanax and zoloft. Similar increases can be observed in a series of other antidepressants. ${ }^{17}$ The same lag in the spike is observed here as with symptoms.

Finally the surge in symptoms and side effects is to a large extend uniform across countries. Figures 10 and 11 show symptoms and side effects searches in the G8 countries. We see a surge in both kinds of searches around the TARP date. We note slight delays in all European countries but France. Japan and Russia start surging before the TARP date although in the case of Russia the search activity for side effects appears to be too small (an interesting fact in itself considering football searches between say Germany and Russia are comparable in volume across time). The numbers are relative so that volumes are not comparable across countries.

\subsection{Further Discussion}

We observe a surge in malaise searches across the G8 and a closer look at the US and German case reveals a delay for the German surge which is in concordance with the timeline of the crisis. These facts reasonably establish that the shock of the crisis causes the surge. The obvious hypothesis which can cause the spikes in these signals is that the crisis causes more people to be interested in symptoms or side effects information and hence more people are experiencing malaise of some kind (and take medication of some kind in the case of side effects). This is our preferred

\footnotetext{
${ }^{17}$ Side effect searches in Germany (nebenwirkungen) spike similarly.
} 
interpretation and in order to strengthen it we need to rebut alternative hypotheses which can explain the signal spikes without increased malaise.

The alternative hypotheses which we need to rebut are those which attempt to explain the spikes in malaise searches without an increase in malaise. These stem from the reasonable assertion that the probability of uttering a certain word increases with the time or volume of utterance just like the probability to find a word in a text increases with the text's size. Alternative theories then propose that the signal spikes are not due to increase in malaise but to increased "reporting" due to changes in the amount of time individuals allocate to searching.

In order to facilitate this discussion we need two formal definitions of the signal strength search volumes express. An individual's interest in certain documents (and not others) is assumed to be a function of the individual's state and hence so are the individual's search queries which attempt to discover these documents. These queries are therefore utterances worth being investigated and the monitoring of these utterances may be thought of as an involuntary panel survey. On the aggregate level it is natural to define the signal $s_{t}(q)$ of a search query $q$ or a disjunction thereof in a given reference time interval $t$. There are two obvious ways to do this. The first way is to simply count the number of respondents who searched for $q$ within $t$ and divide that by the number of respondents who searched for anything within $t$. A second definition is to weigh the contributions of individuals to the signal with a continuous function between $[0,1]$ by dividing the number of times they searched for $q$ by the total number of their searches (one could also weigh by the number of clicks on the results of the searches). The sum of all weighted contributions is then divided by the weighted sum of all searches within $t$ and that will be the signal of $q$ in that time interval $t$. We do not know which definition Google Insights uses but we will try to make due without that knowledge.

The main difference between the two definitions is best captured by an epidemiological metaphor: the former definition counts the number of infections and is blind to their severity whereas the latter captures the severity. This means the latter cannot separate between surges in severity and surges in contagion.

One of the competing hypotheses which would explain the signal spikes without increased malaise suggests that the number of people (or even the group of people) who perform these malaise searches may remain fixed despite a strengthening signal. With our second signal definition this 
would mean that those experiencing malaise of some kind do so more intensely (starting at time $\mathrm{t}=\mathrm{TARP}$ ) but no new cases are added. It is certainly likely that say individuals with an anxiety vulnerability experience more of it in any type of increase in stress but that alone would not suffice to explain the phenomenon as we know from the Gallup well-being index that the self reported malaise increased in the crisis very much at the same time as the malaise searches indicate.

Another, quite naturally arising, competing hypothesis proposes that for example an ailing sports fan with limited leisure time may under normal circumstances first search for game results, rankings and interviews and may likely neglect searching for symptoms. If for some reason however (like unemployment or slow business in the recession) the respondent spends more time searching it may become more likely that he searches for symptoms. This way we get a spike in the signal but it reveals malaise which was there to begin with. The crisis would then not cause new malaise but it would cause indirectly more reporting thereof, because the real effect is that people have more time. Data by Forrester ${ }^{18}$ (forrester.com) shows that while internet use has been increasing since 2004 it actually declined in the crisis (i.e. from 2008 to 2009). This contradicts our alternative hypothesis since it implies increased internet time. Moreover, the signal remained flat all the way through the increasing internet use between 2004-2008. For this hypothesis to remain true we would need to have preexisting malaise being revealed and at the same time non malaise searchers spend less time on the internet. This would imply that for some reason the crisis endows ailing people with more time and healthy ones with less. While this could partially be the case (for example if ill people are fired first and the healthy ones still employed are now overworked) it does not seem to suffice as the sole explanation. This is most obvious in the case of side effects searches.

Another way in which increased signal due to newly revealed preexisting malaise can occur is because on financial grounds a doctor's visit is substituted by self-diagnosis. This could hold in the case of the US but it would certainly not hold in the German case where a more comprehensive social state is in place. Overall it is hard to imagine how this hypothesis would fit with side effect searches which are very likely to be related to new treatments. In this case it would mean that at time $t=$ TARP medicated people decide to explore side effects they had all along.

\footnotetext{
${ }^{18}$ The report is proprietary but we can point the reader here http://news.cnet.com/8301-1023_3-10297935-93. html.
} 


\section{Conclusions}

We presented internet search data to show that the crisis impacted health and well-being and corroborated this evidence with data from different more traditional sources. We performed due diligence checks in order to exclude several alternative hypotheses. The impact of the crisis on health and well-being is mainly due to widespread welfare erosion but may have well been exacerbated by excessive reporting which produced what we call irrational sullenness. Whichever the reason its impact is real. Search data for symptoms and side effects across the G8 countries where internet penetration is high and such data are more reliable shows that mental, emotional and physical discomfort was severely affected very much in concordance with intensity of the crisis and its contagion timeline.

Internet as a source of data for the social sciences and in particular search data which can be viewed as a sort of involuntary panel survey can in our opinion be valuable for the social sciences. This is demonstrated via Google Insights which, despite the loss of information aggregation causes, is shown to provide us with uniques insights into large scale processes. The intensities of symptoms and side effects searches provide the basis for health indicators capturing self-diagnosis and treatment respectively. We believe that with access to search microdata and more sophisticated techniques these indicators can be important for public health policy making and prevention. 


\section{References}

Arinaminpathy, N. \& Dye, C. (2010). Health in financial crises: economic recession and tuberculosis in Central and Eastern Europe. Journal of The Royal Society Interface, 7(52), 1559-1569. URL http://rsif. royalsocietypublishing.org/content/7/52/1559. abstract.

Askitas, N. \& Zimmermann, K. F. (2009). Google econometrics and unemployment forecasting. Applied Economics Quarterly, 55(2), 107-120.

Bersier, F. (2010). Towards Better Policy and Practice Using Real-Time Data. SSRN eLibrary.

Brenner, M. H. (1973). Mental Illness and the Economy. Cambridge: Harvard University Press.

Brenner, M. H. (1975). Trends in Alcohol Consumption and Associated Illnesses: Some Effects of Economic Changes. American Journal of Public Health, LXV, pp. 1279-1292.

Brenner, M. H. (September 15, 1979). Mortality and the National Economy. The Lancet, pp. 568-573.

CDC (2010). Centers for disease control. National Vital Statistics Reports.

Celjo-Hrhager, S. \& Niessen, A. (2006). How do self-fulfilling prophecies affect financial ratings? - an experimental study. CFR-Working Paper No. 06-13.

Clark, A. E. \& Oswald, A. J. (1994). Unhappiness and unemployment. The Economic Journal, 104 (424), pp. 648-659. URL http://www.jstor.org/stable/2234639.

Classen, T. J. \& Dunn, R. A. (2011). The effect of job loss and unemployment duration on suicide risk in the united states: a new look using mass-layoffs and unemployment duration. Health Economics, pp. n/a-n/a. URL http://dx.doi.org/10.1002/hec. 1719.

D'Amuri, F. \& Marcucci, J. (2010). Google It. Forecasting the US Unemployment Rate with A Google Job Search Index. SSRN eLibrary.

Frey, B. S. (2008). Happiness: a revolution in economics. CES.

G. C. Murphy, J. A. A. (1 March 1999). The effect of unemployment on mental health. Journal of Occupational and Organizational Psychology, 72, 83-99(17).

Ginsberg, J., Mohebbi, M. H., Patel, R. S., Brammer, L., Smolinski, M. S., \& Brilliant, L. (2009). Detecting influenza epidemics using search engine query data. Nature.

Kholodilin, K. A., Podstawski, M., \& Siliverstovs, B. (2010). Do Google Searches Help in Nowcasting Private Consumption? A Real-Time Evidence for the US. SSRN eLibrary.

Kholodilin, K. A., Podstawski, M., Siliverstovs, B., \& Bürgi, C. (2009). Google Searches as a Means of Improving the Nowcasts of Key Macroeconomic Variables. SSRN eLibrary.

Kulkarni, R., Haynes, K. E., Stough, R. R., \& Paelinck, J. H. (2009). Forecasting Housing Prices with Google Econometrics. SSRN eLibrary.

Lewis, G. \& Sloggett, A. (1998). Suicide, deprivation, and unemployment: record linkage study. BMJ, 317(7168), $1283-1286$.

Linn, M. W., Sandifer, R., \& Stein, S. (1985). Effects of unemployment on mental and physical health. Am J Public Health, $75(5), 502-506$.

Martin-Moreno, J. M., Alfonso-Sanchez, J. L., Harris, M., \& Lopez-Valcarcel, B. G. (2010). The effects of the financial crisis on primary prevention of cancer. Eur J Cancer (in press)., 46(14), 2525-2533.

Narayan, P. K. (2010). Modelling health and output at business cycle horizons for the usa. Health Economics, 19(7), 872-880. URL http://dx.doi.org/10.1002/hec.1524.

Pass, G., Chowdhury, A., \& Torgeson, C. (2006). A picture of search. In: InfoScale '06: Proceedings of the 1st international conference on Scalable information systems.

Porche, D. J. (2005). Depression in Men. The Journal of Nurse Practicioners, 1(3), 138-139.

Ruhm, C. J. (2000). Are recessions good for your health?*. Quarterly Journal of Economics, 115(2), 617-650.

Schmidt, T. \& Vosen, S. (2009). Forecasting Private Consumption: Survey-Based Indicators vs. Google Trends. SSRN eLibrary.

Schmidt, T. \& Vosen, S. (2010). A monthly consumption indicator for germany based on internet search query data. SSRN eLibrary.

Sims, G. (2010). The Demand for Information. SSRN eLibrary.

Tefft, N. (2011). Insights on unemployment, unemployment insurance, and mental health. Journal of Health Economics, In Press, Corrected Proof, -. URL http://www.sciencedirect.com/science/article/ B6V8K-521NW4T-1/2/1e9b5d6ca52d13e0134f378b3f54fbca.

Varian, H. R. \& Choi, H. (2009). Predicting the Present with Google Trends. SSRN eLibrary.

Wilcox, W. B. (2009). The Great Recession's Silver Lining.

Wilhelm, K. A. (2010). Men and Depression. Australian Family Physician, 38(3), 102-105. 

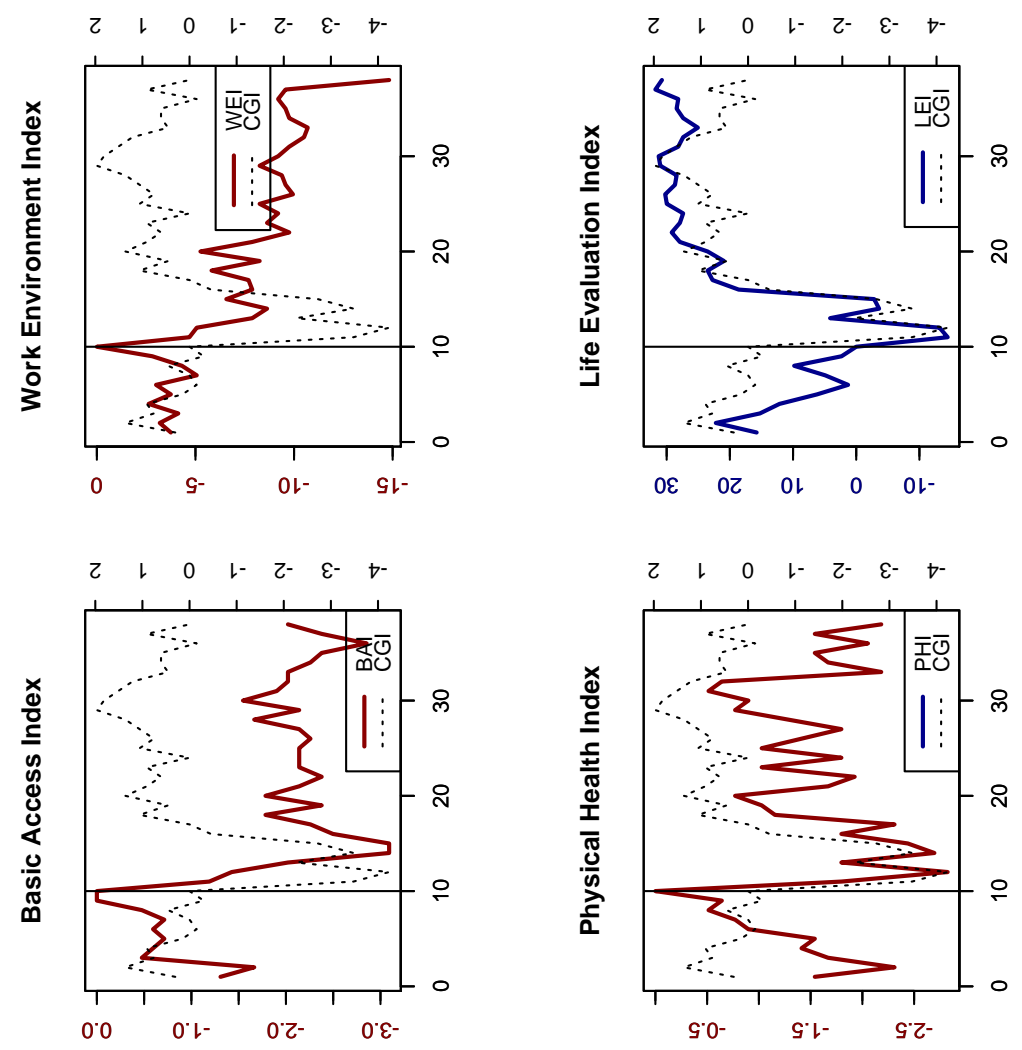

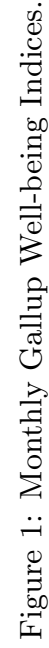
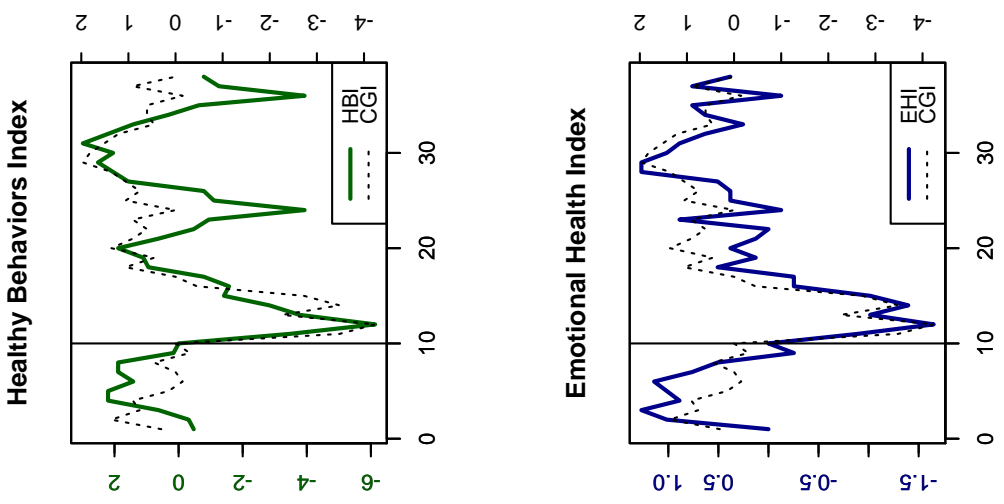

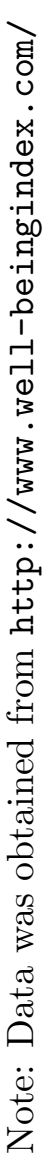



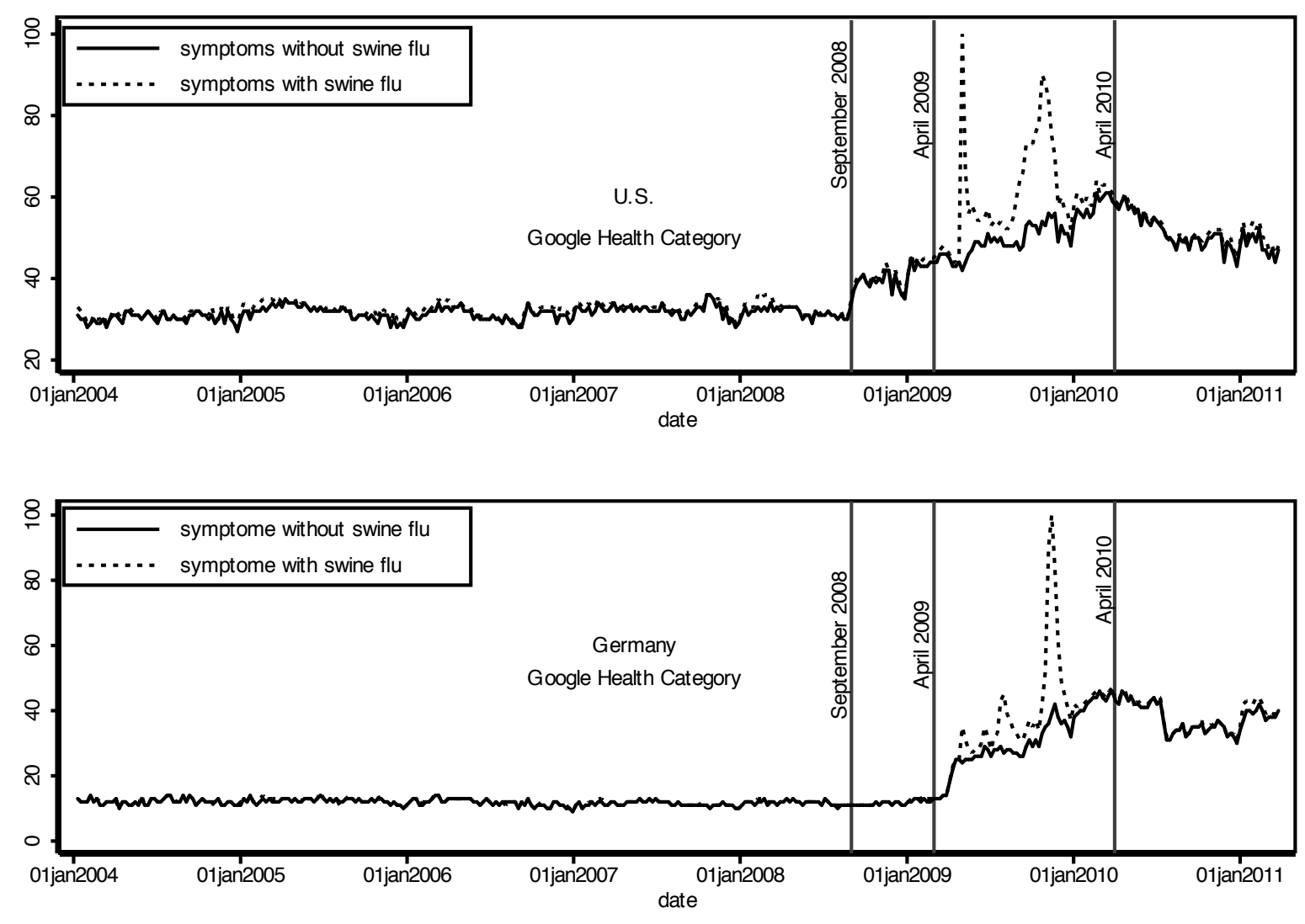

Figure 2: Symptoms searches in the Google Health Category in the US and Germany.

Note: While in the US they surge as early as in September 2008 (first vertical line) for Germany they do not until April 2009 (second vertical line). By April 2010 (third line) the searches more than doubled compared to the level before September 2008. We use symptoms and symptoms $-\mathrm{flu}-$ swine -h1n1 in the US and symptome and symptome -grippe -h1n1 -schweinegrippe in Germany. 

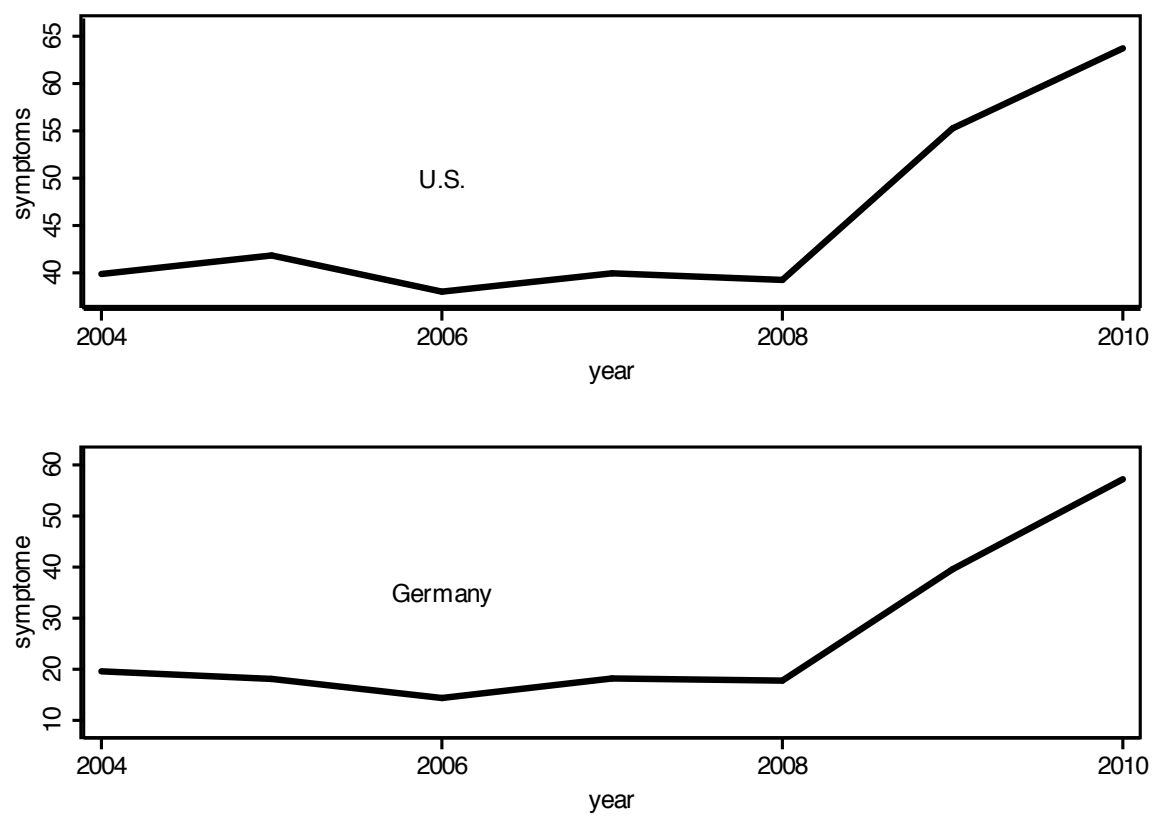

Figure 3: Annual averages of ratios of symptoms to football searches in the US and Germany.

Note: We use football and symptoms -flu -swine -h1n1 in the US and fussball + fußball and symptome -grippe -h1n1 -schweinegrippe in Germany. 


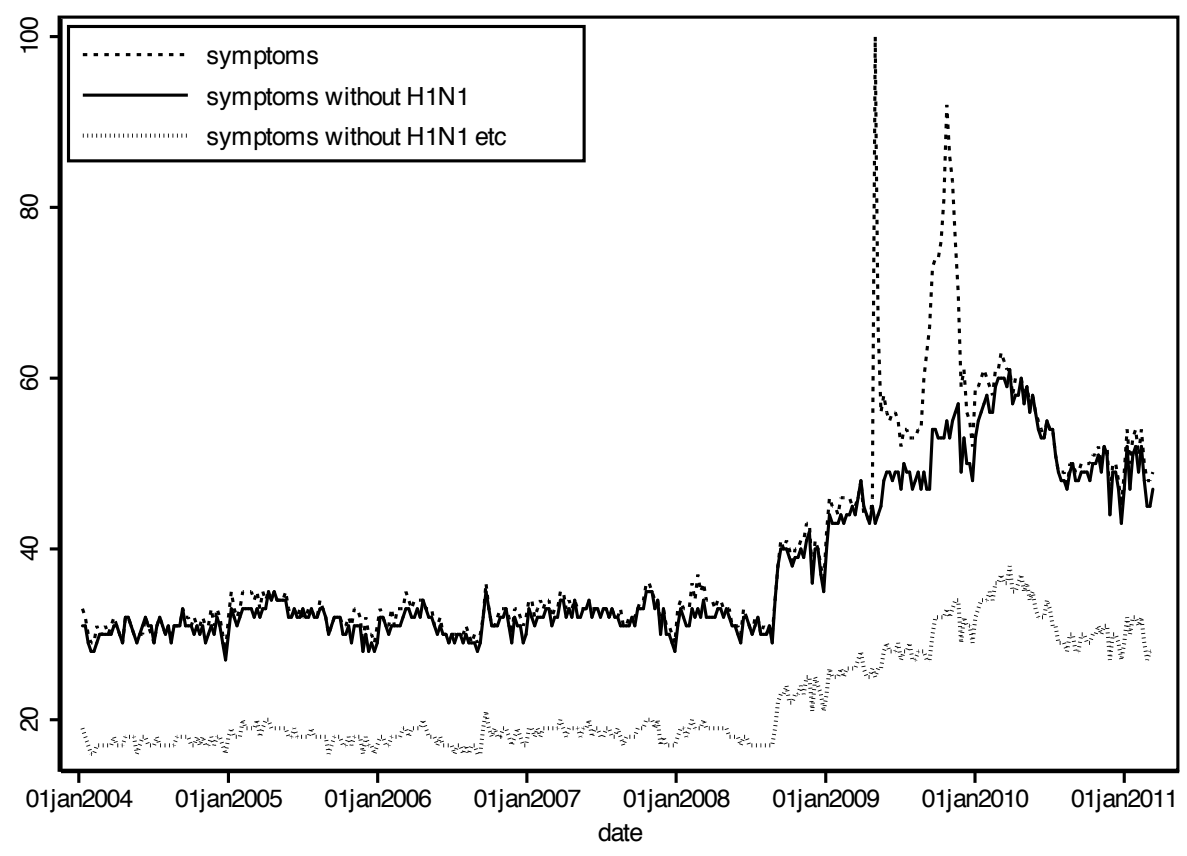

Figure 4: A breakdown of symptoms searches in the US shows us that all symptoms searches increase.

Note: Even after we take out the ones on: H1N1, swine, flu, old, kidney, menopause, medical, herpes, withdrawal, salmonella, and, allergy, infection, lyme, diabetes, aids, hiv, stroke, yeast, herpes, thyroid, autism, cancer, heart, attack, depression, anxiety, early, pregnancy. We stopped this exercise at the 30 word perr query limit of Google Insights. The marvels of the long tail remain at this point a mystery. 

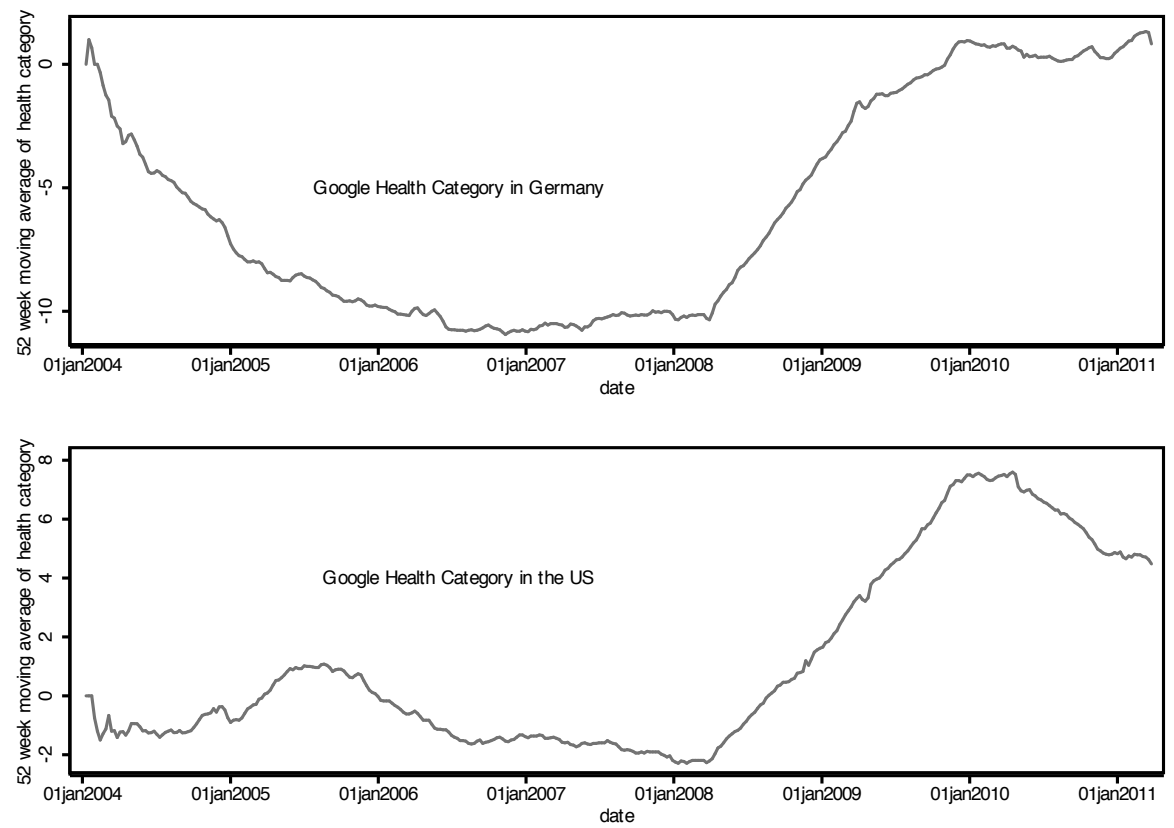

Figure 5: The growth of the Google Category: Health.

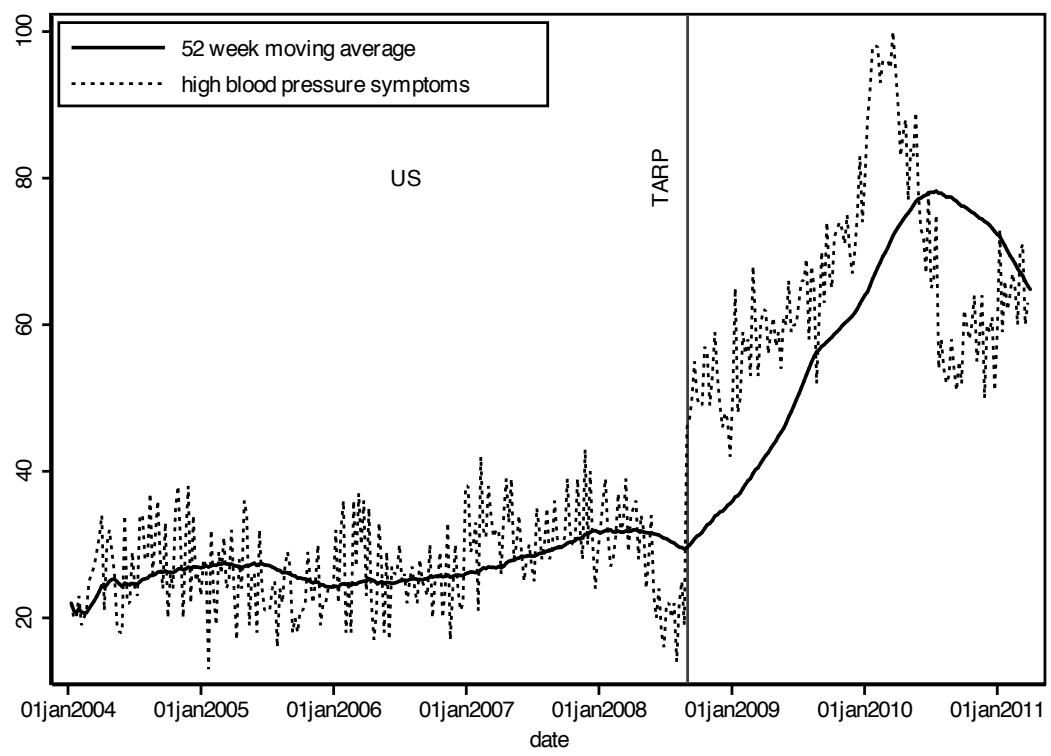

Figure 6: Search intensity of 'high blood pressure symptoms' 


\section{U.S.}
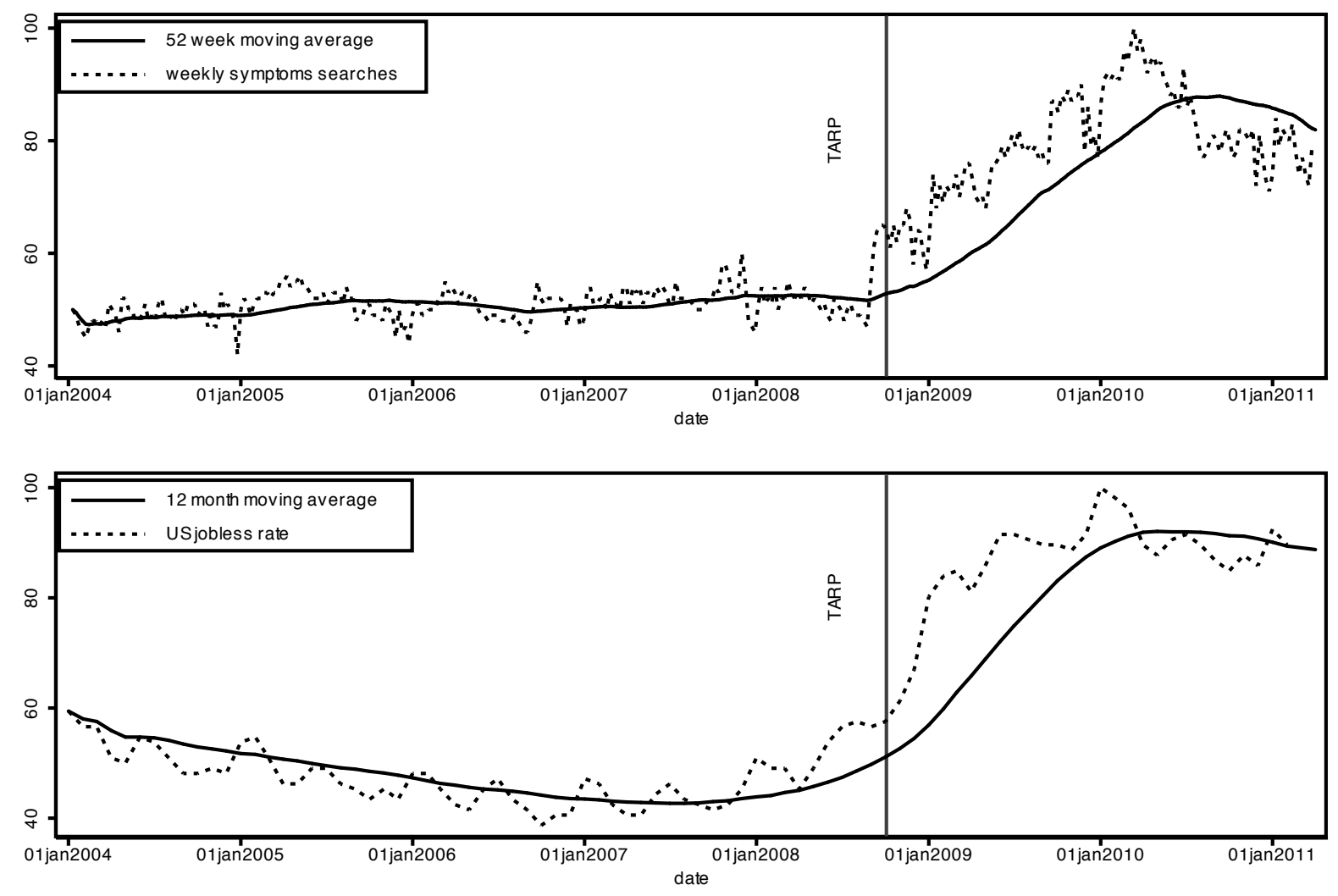

Figure 7: Symptoms searches compared to change in the labor market 

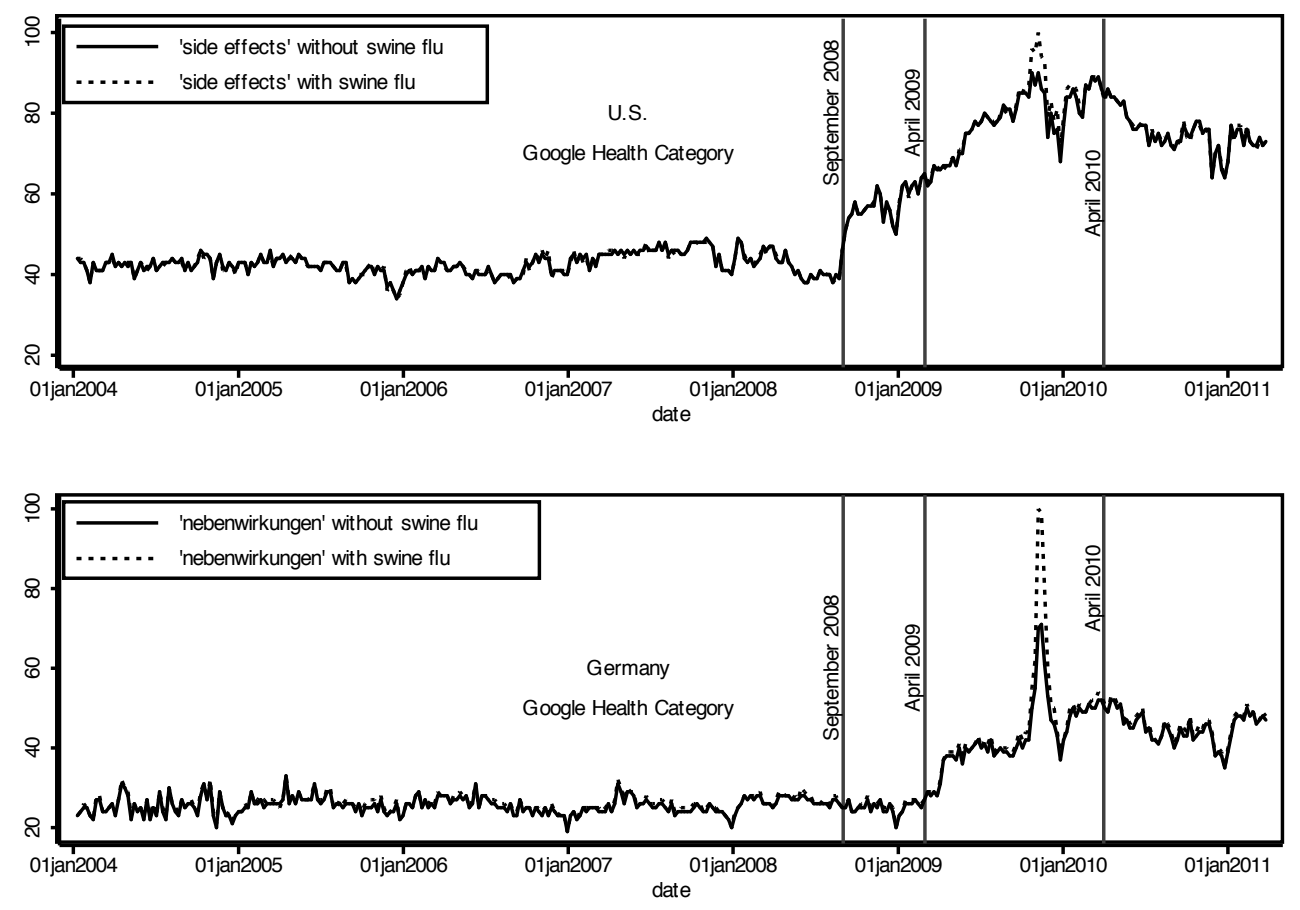

Figure 8: 'Side effects' search intensity: weekly series and smoothing 

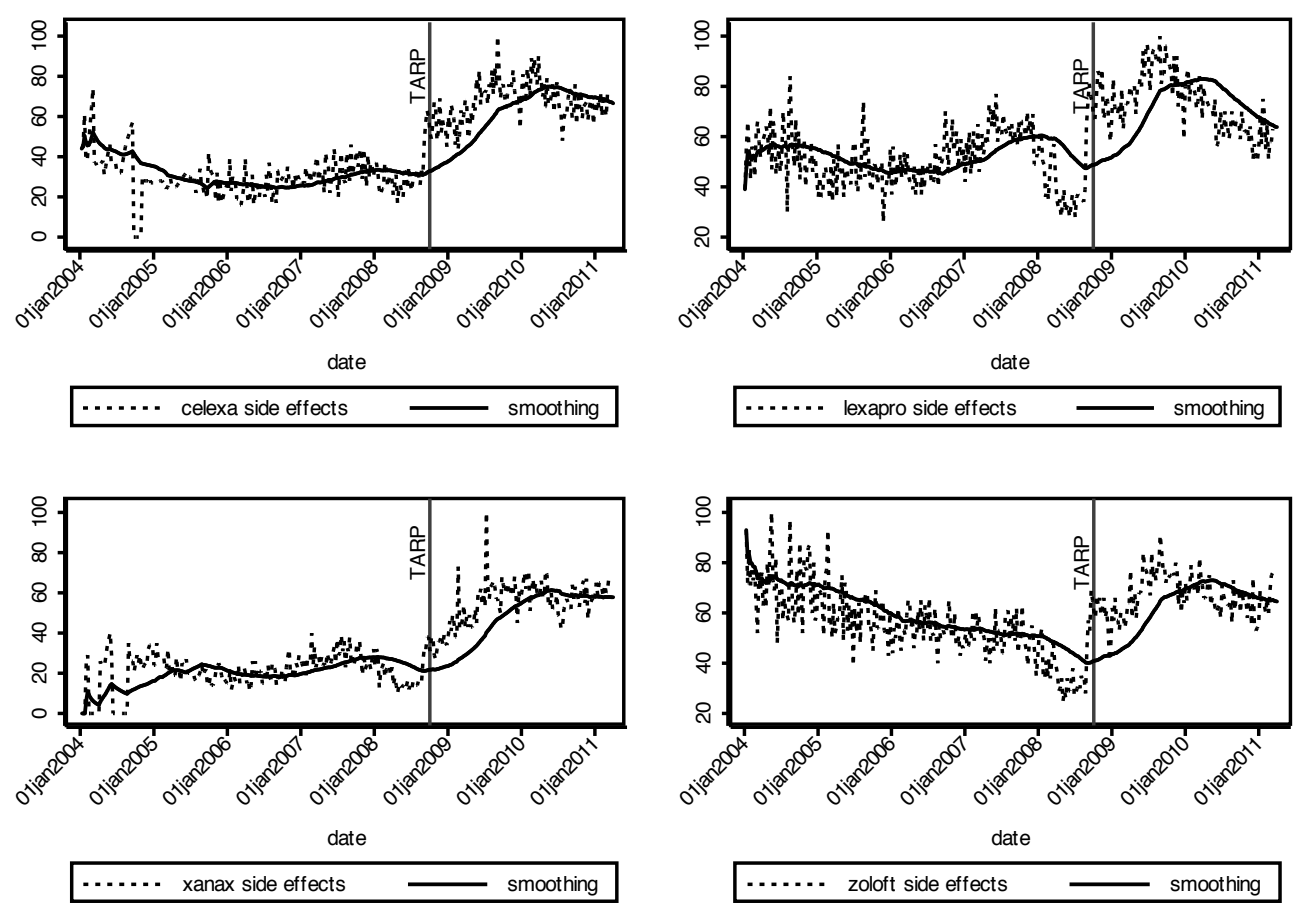

Figure 9: Searches for the side effects of 4 well known antidepressants: celexa, lexapro, xanax and zoloft 

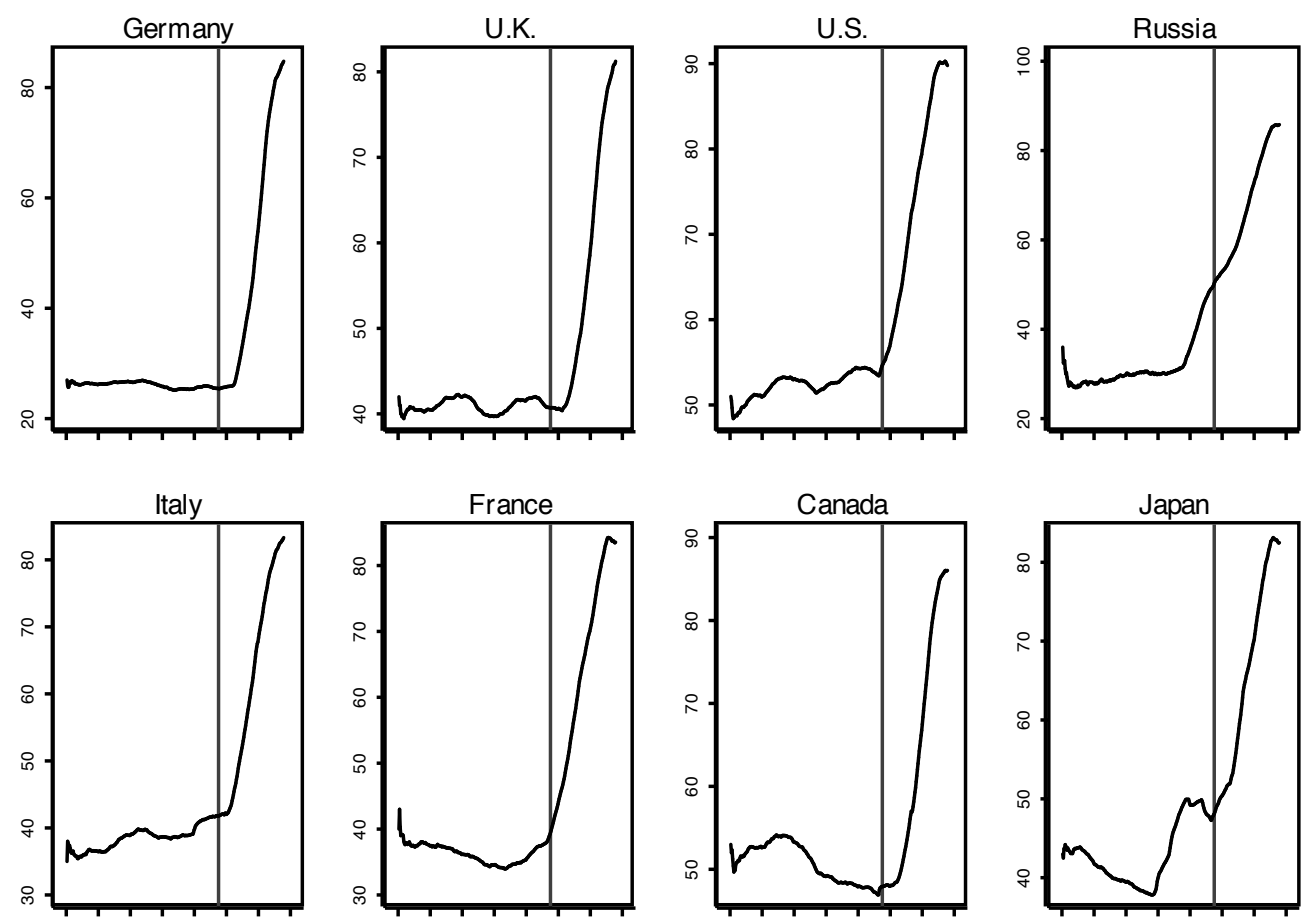

Figure 10: Symptoms searches in the G8 

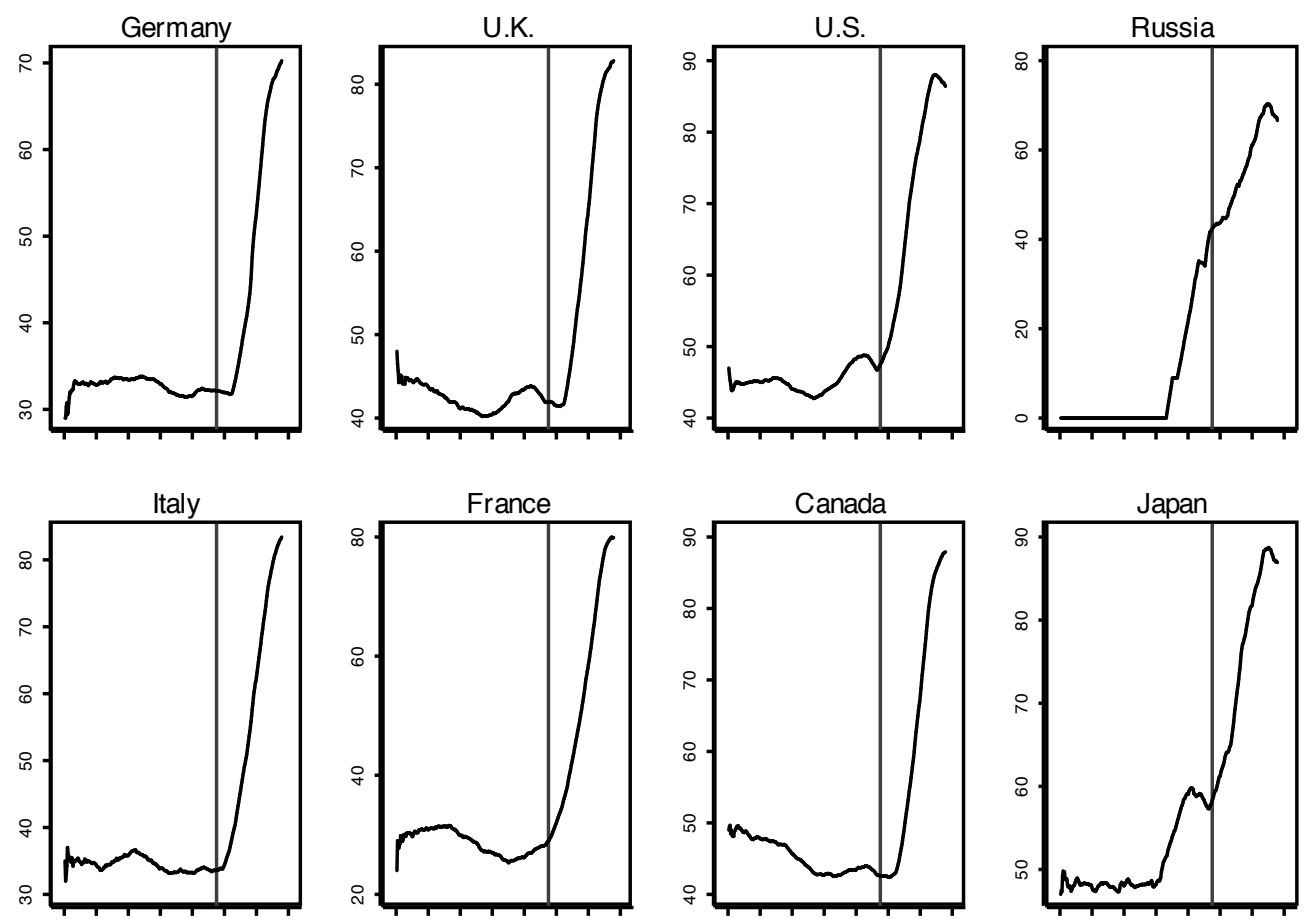

Figure 11: Side effects searches in the G8 